\title{
Religiosidade popular na Capela dos Aflitos
}

DOI: https://doi.org/10.35168/2176-896X.UTP.Tuiuti.2020.Vol7.N62.pp4-17

Vera Irene Jurkevics

Professora da Universidade Tuiuti do Paraná (UTP) e da Faculdade Dr. Leocádio José Correia (FALEC). Graduada em História pela Universidade de São Paulo - USP, mestrado em História pela Universidade Estadual Paulista Júlio de Mesquita Filho - UNESP e doutorado em História pela Universidade Federal do Paraná - UFPR. Membro Fundador do Núcleo Paranaense de Pesquisa em Religião (NUPPER).E-mail: vera.jurkevics@utp.br 


\section{Religiosidade popular na Capela dos Aflitos}

\section{Resumo}

Esta pesquisa, como parte de um estudo mais amplo acerca de expressões e manifestações de fé popular, visa entender como, mesmo à parte da institucionalidade, se desenvolveu o culto a Francisco José das Chagas, conhecido como Chaguinhas, o "Santinho da Liberdade", na Capela Nossa Senhora dos Aflitos, no bairro da Liberdade, na capital paulista. Da mesma forma como tantas outras santidades populares, essa foi construída a partir de uma morte marcada pela tragicidade e que provocou um impacto emocional em umas tantas pessoas presentes naquele contexto e que não tardaram a atribuir ao réu sentenciado a morte, no final do período colonial, poderes excepcionais de intercessão celestial, resultando deste então, o testemunho de um grande número de graças alcançadas. Apesar deste culto ocorrer no interior de uma capela consagrada, seu caráter é oficioso, pois Chaguinhas não faz parte do panteão oficial, o que absolutamente parece não diminuir a fé daqueles que buscam esperança e alento para suas próprias vidas.

Palavras-chave: Religiosidade Popular. Santidade. Chaguinhas. 


\section{Popular religiosity in the Aflitos Chapel}

\section{Abstract}

This research, as part of a broader study on expressions and manifestations of popular faith, aims to understand how, even apart from the institutionality, the cult of Francisco José das Chagas, known as Chaguinhas, the "Santinho da Liberdade" in the Nossa Senhora dos Aflitos Chapel, in the Liberdade neighborhood, in the city of São Paulo. Like so many other popular sanctities, this one was built from a death marked by tragicism and that caused an emotional impact on a few people present in that context and who were quick to attribute to the defendant sentenced to death, still at the end of the period colonial, exceptional powers of celestial intercession, resulting in this then the testimony of a great number of graces reached. Although this cult takes place inside a consecrated chapel, its character is unofficial, since Chaguinhas is not part of the official pantheon, which absolutely does not seem to diminish the faith of those who seek hope and encouragement for their own lives.

Keywords: Popular Religiosity. Holiness. Chaguinhas. 


\section{Religiosidade popular na Capela dos Aflitos}

Como herança portuguesa, a população brasileira teve como forte característica, uma religiosidade menos pautada, em introspecções espirituais, já que sua prática recaia mais nos atos exteriores de culto, sobretudo os rituais aos santos católicos, com altares dedicados a eles, além de expressões piedosas variadas, como rezas, romarias e procissões de santos padroeiros. Nesse contexto, surgiram incontáveis confrarias e irmandades, encarregadas dos rituais devocionais de diferentes grupos que demonstraram, grande organização e capacidade de mobilização popular.

Ao longo do tempo, e em função das condições de ocupação das terras brasileiras, tais práticas religiosas se desdobraram, incorporando outras expressões de fé e de santidades não legitimadas pela Igreja, os chamados santos populares. Por isso, analisar hoje questões referentes às religiões e às religiosidades, implica irmos além do estudo das instituições cristalizadas de religiosidade, trazendo para as discussões outros objetos, os sujeitos religiosos.

Assim, penetrar nesse campo das práticas religiosas é, a um só tempo, romper com antigos parâmetros historiográficos, em que as análises se pautavam, sobretudo, nas relações internas de poder, no âmbito de sua hierarquia e nas externas, principalmente com o Estado e, avançar na dialogia dos discursos, captando o trânsito entre o institucional e o desclericalizado, entre a ortodoxia e a heterodoxia, entre o oficial e o oficioso. Além disso, procurar desvendar o significado das práticas de culto e de suas formas devocionais, identificando suas rupturas e permanências no universo do sagrado.

Destacamos que nosso campo de investigação situa-se sobretudo nos laços, forjados ao longo do tempo, entre os ditames da fé e da vida comum, cotidiana, de homens e mulheres, destituídos de vez e voz, dentro das institucionalidades religiosas, mas que, sem dúvida, têm construído um patrimônio cultural inestimável. Por isso, defendemos que a Religiosidade Popular, enquanto espaço de análise se configura como um lócus de muitas ressignificações e possibilita a reinserção de símbolos e objetos cujo sentido varia de um regionalismo para outro, requerendo, portanto, do olhar que o analisa, perceber suas especificidades, olhar suas cores, degustar seus sabores, sentir 


\section{Religiosidade popular na Capela dos Aflitos}

seus cheiros, penetrar em seus segredos, considerando-os, tanto em suas especificidades, quanto em seu aspecto sociocultural e histórico.

Nesse sentido, apontamos um claro exemplo de Religiosidade Popular, nascido de uma vivência independente das diretrizes institucionais, mas não totalmente desconectada delas, exemplo típico do conceito bakthiniano de circularidade cultural, em que, os elementos predominantes numa dada realidade, ora são institucionais, ora fogem da tutela legitimadora, de forma alternada, resvalandose continuamente, sem que um consiga neutralizar totalmente o outro. Antes, apesar de suas características próprias, esses elementos apresentam uma dinâmica, tecida de trocas recíprocas, que pode ser percebida, dentro de uma perspectiva histórica, de incessantes reformulações, em que, segundo Michel Vovelle (1987) não há fronteiras fixas, nem modelos invariáveis.

Nessa perspectiva encontra-se a devoção a Chaguinhas ou "o santinho da Liberdade", iniciada pouco antes da instalação do Império brasileiro e mantida até hoje na Capela de Nossa Senhora dos Aflitos, ou como é mais conhecida, a Capela dos Aflitos.

\section{Martírio e fé}

A Capela Nossa Senhora dos Aflitos localiza-se no bairro da Liberdade, um dos mais tradicionais da cidade de São Paulo, tido como o maior reduto asiático, especialmente de japoneses, constituindose na Japantown ${ }^{1}$ brasileira. Atualmente caracteriza-se por estimular o imaginário de paulistanos e turistas, com ruas e avenidas enfeitadas por lanternas vermelhas, além de muitos outros atrativos culturais $^{2}$ e de um amplo comércio de produtos para atender às coletividades orientais, que ali se estabeleceram no começo do século XX.

1 Numa clara alusão à denominação dada às regiões urbanas de expressiva população chinesa em meio a uma sociedade não chinesa, a exemplo da Chinatown de Nova lorque e a de Los Angeles, nos Estados Unidos, ou ainda a de Montreal, no Canadá.

2 Com destaque para o Museu Histórico da Imigração Japonesa com rico acerco de objetos, fotografias, cartas e documentos pessoais. 


\section{Religiosidade popular na Capela dos Aflitos}

Assim como outras localidades da cidade paulistana, o espaço que hoje abriga a Liberdade surgiu a partir do loteamento de antigas chácaras, quando o bairro passou por um processo de ocupação mais intenso e os imigrantes conseguiam se estabelecer, alugando os porões de casas das ladeiras íngremes, transformados em quartos que chegavam a abrigar famílias inteiras. Gradativamente passaram a desenvolver atividades comerciais, como um empório, depois uma casa de tofu, o queijo japonês, logo mais, outra produzia o manju, o tradicional doce japonês, e sequencialmente surgiram os agenciadores de empregos, resultando, com o passar do tempo, da "rua dos japoneses" (SAKURAI, 1993).

No entanto, a história desse bairro, no final do período colonial, foi marcada por fatos dramáticos. De acordo com Paulo Cursino de Moura (1980) até o início do século XIX, tratava-se de uma região periférica, praticamente desabitada, mesmo sendo passagem obrigatória dos que, partindo do centro, se dirigiam para os lados distantes de Santo Amaro, na zona sul da cidade, como também dos tropeiros que se destinavam ao litoral, responsáveis pelo abastecimento de gado. Naquela época, essa região era conhecida como Campo da Forca, local de execução de escravos, de forros e de criminosos, em geral.

Segundo José Alfredo Vidigal Pontes (2003), os sentenciados à pena de morte ${ }^{3}$ aguardavam as punições na Capela dos Aflitos, construída em 1779, agrilhoados à parede e com sentinelas nas portas do templo que ficava no fim de um beco, mais tarde chamado de Beco dos Aflitos. Depois de supliciados, os condenados eram sepultados no terreno que abrigava a pequena capela, "impedidos de repousar em solo sagrado no interior das igrejas ou em seus adros, o meio mais eficaz para garantir a salvação das almas, conforme o costume vigente", (CAMARGO, 2017). Por isso, o Cemitério dos Aflitos, datado de 1775, é tido como o primeiro extramuros, "a céu aberto", da cidade de São Paulo.

3 Também chamada de morte suja porque, em função do relaxamento dos esfíncteres, geralmente ocorria liberação de urina, fezes e até mesmo sêmen, 0 que era considerado ofensivo à moral do condenado e que também atingia a de seus familiares. 


\section{Religiosidade popular na Capela dos Aflitos}

Na segunda metade do século XIX, de acordo com Luís Soares de Camargo (2017), a visão higienista que marcou as políticas públicas e sanitárias, amparadas em nova legislação, proibiram os sepultamentos dentro das igrejas, ou sob covas rasas, atestando a insalubridade de tais práticas, em função dos "miasmas pestilentos" dos corpos em decomposição, exigindo, por isso, que a pronta edificação dos cemitérios deveria obedecer, além de outras exigências, uma considerável distância do núcleo populacional.

Em decorrência de um surto de varíola que abateu a cidade paulista naquele mesmo período, a Câmara Pública nomeou uma comissão encarregada de procurar um local para a implantação de um novo local para o sepultamento dos mortos. A decisão recaiu para uma das saídas da cidade, na "estrada para Sorocaba", onde, praticamente, não havia moradores. Assim se deu a construção e a inauguração do Cemitério da Consolação, o primeiro cemitério público da cidade de São Paulo e o desaparecimento das valas comuns do antigo Cemitério dos Aflitos, dele só restando a capela de mesmo nome. Tempos depois, D. Lino Deodato Rodrigues, então bispo da diocese paulista, mandou retirar os despojos do antigo cemitério, lotear a área e vender os terrenos, cujos recursos foram destinados às obras da Catedral da Sé, em início de construção.

Relatos apontam que naquela região, no Campo da Forca, às vésperas da Independência, ocorreram cenas de extrema crueldade. Autoridades provinciais a serviço do regente Pedro de Alcântara, tentando abafar um levante nativista, na cidade de Santos, no litoral paulista, ocorrido em meados de 1821, promoveram duas execuções que causaram grande clamor popular, a de Joaquim José Cotindiba e a do cabo Francisco José das Chagas, conhecido como Chaguinhas, acusados de liderarem uma centena de amotinados do Primeiro Batalhão de Caçadores de Santos ${ }^{4}$ que reivindicavam muitos salários atrasados, aumento de soldo e igualdade no tratamento militar dispensado a soldados portugueses e brasileiros.

4 Caçadores eram soldados que serviam a pé ou a cavalo que, historicamente na Europa, haviam sido recrutados entre os caçadores, incorporados às forças de defesa de sua região, com suas armas de caça. Geralmente atuavam como batedores, mensageiros ou ainda como atiradores, em proveito do corpo principal das tropas. 


\section{Religiosidade popular na Capela dos Aflitos}

O conflito entre "os filhos da terra" e os "renóis" resultou num ataque a uma embarcação portuguesa, no Porto de Santos, o que levou os dois soldados brasileiros à prisão, seu encaminhamento para São Paulo de Piratininga e, logo depois sentenciados à forca, numa clara demonstração de que não seriam permitidos levantes, de qualquer natureza, e que os oficiais controlavam tanto a população, como a soldadesca em tempos pré independência.

O cronista santista Edmundo Amaral, assim apresentou a cena do cortejo que levou o cabo Chaguinhas à morte:

$\mathrm{Na}$ frente alçada, balançava num ritmo de passos, uma cruz de prata reflete chamas de vela; logo após, entre um quadrado de lanças, junto ao confessor, descalço, sereno, magnífico, passa Chaguinhas para a forca. Leva uma alva longa e talar que quase arrasta no lajedo úmido, nos pulsos encruzados balança uma cadeia grossa e do forte pende-lhe um baraço novo. Atrás dentre os rebuços negros e feltros afunilados, sacode-se na fria brisa da manhã a bandeira da Misericórdia e sob os sobradões de beirais abatidos, como capuzes, segue a corte para a forca (1932 p. 43).

Interessante observar que na descrição acima não há qualquer indicação de Joaquim José Cotindiba, no entanto, os demais relatos, referentes a este episódio, testemunham sua participação e seu enforcamento, com morte rápida por asfixia. Mas o segundo condenado não teria tido a mesma sorte, uma vez que a corda no patíbulo de enforcamento, a mesma do sentenciado anterior, arrebentou na primeira tentativa de sufocamento e o réu caiu no chão. Aqueles que assistiam à execução intercederam por sua liberdade, como rezava a tradição, de indultar o condenado ou de comutar sua pena. Para o povo ali presente, era a vontade divina se manifestando, certamente mais poderosa que a dos homens.

5 Outros exemplos ilustram o forte sentimento nativista, antes e depois desse episódio, como por exemplo: a Aclamação de Bueno (1641, Vila de São Paulo), a Guerra dos Emboabas (1707-09, capitania de Minas Gerais) e a dos Mascates (1710-11, entre as cidades de Olinda e Recife), além das de caráter emancipatório como a Revolta dos Alfaiates (ou Conjuração Baiana, 1798-99) e a Revolta Pernambucana (ou dos Padres, 1917). 


\section{Religiosidade popular na Capela dos Aflitos}

E, naturalmente movido pelo imaginário, e pelo ideal nacionalista, associou esse enforcamento a outro e, assim, Chaguinhas, naquele momento era transformado no Tiradentes paulistano.

Conforme Camargo (2017) depois do ocorrido, e suspensa temporariamente a execução, houve um debate parlamentar ocorrido em plenário sobre aquele enforcamento, em que o povo não somente comovido, mas indignado, dirigiu-se ao Palácio de Governo exigindo indulto, mas o pedido de clemência não foi atendido, possivelmente dado o caráter nativista da acusação. Apesar de não termos indicação de quantos dias se passaram, é certo que, novamente o laço foi armado na parte superior do patíbulo e quando o corpo foi jogado ao ar, a corda teria se partido pela segunda vez, quando alguém, no meio da multidão teria gritado "Milagre!". Na terceira tentativa, que se supõe, tenha ocorrido logo em seguida, por faltar mais corda para um novo nó, o carrasco teria providenciado uma tira de couro que não foi capaz de provocar totalmente o sufocamento, por isso o semimorto acabou morrendo à base de pauladas (AMARAL, 1932).

Naquele contexto, para muitos, a prova de sua inocência estava ali: na teimosia da corda em se negar a enforcar e assim, Chaguinhas transcendendo a condição de herói, "O Tiradentes paulistano", passou a ser revestido de uma aura de santidade, já que os moradores da região, acompanhados por membros da Irmandade da Misericórdia ${ }^{6}$ consagraram-lhe a condição de mártir, fincaram uma cruz no solo, para demarcar o local do suplício, passando a orar e acender velas, em sua intenção e das Almas do Purgatório. Há quem dissesse que no calor da indignação popular, com um desfecho tão cruel, as velas acessas não se apagavam, nem com o vento, nem a chuva, até que tivessem queimado até o finzinho do pavio. Sinais evidentes de que ali havia ocorrido uma hierofania, uma manifestação reveladora do sagrado (ELIADE, 2010).

Para o historiador e hagiólogo André Vauchez (1987), o conceito de santidade encontra-se, bem definido, na maior parte das religiões, com um significado ambivalente, mas evocando sempre,

6 Confraria de leigos católicos com finalidades religiosas e de assistência social.

Revista Tuiuti: Ciência e Cultura, v.7 n.62. p. 4-17, Curitiba, 2021 


\section{Religiosidade popular na Capela dos Aflitos}

uma ruptura da condição humana. Assim, nos primórdios da Igreja, foram considerados santos para a comunidade de fiéis, a Virgem, os Apóstolos e os mártires ${ }^{7}$ da religião emergente. Eles que foram torturados, que tiveram seus membros quebrados, que sofreram suplícios com toda sorte de implementos de tortura para que negassem sua fé, acabaram por promover a crença de que o seu espírito, embora no céu, permanecia também nos seus túmulos, o lócus privilegiado para o culto dos mortos. Além disso, o martírio representava o selo da submissão, duplamente legitimada: primeiro porque as comunidades primitivas haviam testemunhado seu martírio e, em segundo, porque mais do que coragem humana "só o poder de Cristo, operando no mártir, poderia sustentá-lo até o final do suplício” (WOODWARD, 1992, p. 60).

Nesse sentido, não parece difícil entender porque os martirizados, independente do que fossem acusados, acabavam por sensibilizar as pessoas, despertando nelas algo que transcendia o mundo material e profano, sem que isso possa ser entendido como degeneração da ortodoxia religiosa.

Por outro lado, mortes trágicas e brutais ${ }^{8}$, se tornam, com frequência, alvo certeiro de novas devoções. Nesse contexto, não demorou muito para que se divulgasse a lenda, incitando o imaginário popular, de que o corpo do supliciado teria sido, depois de morto, retalhado e sua cabeça, rolado pela Ladeira da Forca, indo parar justamente dentro da Capela NS dos Aflitos, no buraco ou vala, onde eram depositados os corpos dos condenados.

Esse cemitério, o primeiro a céu aberto da cidade de São Paulo recebia apenas os corpos de indigentes, escravos e condenados pela Justiça, que por sua condição social não podiam ser enterrados em solo sagrado, nítido exemplo da segregação racial da ordem escravocrata, que dividia os cristãos em brancos, mestiços e negros, e os primeiros em ricos e pobres ou indigentes,

70 relato bíblico de Lucas do martírio de Estevão (Atos dos Apóstolos, 6-7), 0 aponta como o primeiro mártir do cristianismo. Sua prisão, julgamento e morte, corresponde, de certa forma, à própria trajetória do Cristo, inclusive com o pedido de clemência a Deus para seus algozes.

8 Sobretudo de mulheres e crianças, de que já se tem inúmeros exemplos já estudados, um dos quais foi o objeto de nosso doutoramento envolvendo Maria Bueno, a "santinha de Curitiba", que morreu vítima de quase degolamento nos anos finais do século XIX, na capital paranaense. 


\section{Religiosidade popular na Capela dos Aflitos}

contra todos os princípios básicos do cristianismo, já que, nem todos os homens eram irmãos. Cada um era irmão daqueles que fossem de sua raça e condição social.

Entre todos os enterrados ali, o único que se perpetuou na memória popular foi o do soldado Francisco José das Chagas. Daquela época só resta a Capela dos Aflitos ${ }^{9}$ e os devotos acreditavam e muitos, ainda hoje, acreditam que, embaixo do piso de um pequeno cômodo, estejam os restos mortais dos enforcados, entre eles o de Chaguinhas.

Não muito longe dali, no local do enforcamento e em função das circunstâncias em que ocorreu, ao que tudo indica foi fincada uma cruz, reafirmando a sacralização de Chaguinhas, ao mesmo tempo que homenageava outros supliciados. Com o transcorrer do tempo e mantida a prática devocional, aos pés da cruz, começou a ser erigida, em 1887, a Capela Santa Cruz das Almas dos Enforcados ${ }^{10}$, inaugurada quatro anos depois, quando passou a ser denominada somente como Igreja das Almas, e nesse ínterim, o Largo da Forca foi transformado no Largo da Liberdade, denominação que mais tarde se estendeu ao bairro todo.

$\mathrm{Na}$ Capela dos Aflitos, ainda hoje pode-se atestar muitos devotos em oração diante da porta que restou da estrutura da antiga cela. De acordo com uma reportagem do jornal O Estado de São Paulo, de 19/10/2015, naquele local,

Há o costume de se bater três vezes nela e fazer um pedido, muitas vezes em tiras de papel encaixadas nas frestas do batente da porta. No local, flores são depositadas com frequência em homenagem ao santo popular da Liberdade que faz parte de uma lista enorme de nomes não reconhecidos pela Igreja Católica, mas mesmo assim venerados pelo país afora ${ }^{11}$.

9 No final da Rua dos Aflitos, $n^{0} 70$, mais conhecida como Beco dos Aflitos, no Bairro da Liberdade.

10 Hoje na Praça da Liberdade, n⿳0 238, em frente à Estação Liberdade, do Metrô.

11 http://sao.paulo.estadao.com.br/noticias/geral, chaguinha-0-santo-da-liberdade, 1782539. Acesso 11.12.2017.

Revista Tuiuti: Ciência e Cultura, v.7 n.62. p. 4-17, Curitiba, 2021 


\section{Religiosidade popular na Capela dos Aflitos}

$\mathrm{Na}$ realidade se trata de uma capela tão pequena que os fiéis sentam-se nas poucas cadeiras dispostas ao lado do altar, que ficam "lotadas" nas celebrações das missas em intenção de Chaguinhas.

De acordo com relatos jornalísticos, por falta de cuidados, a capela com o passar do tempo se deteriorou, expondo nas paredes a ação de infiltrações. Em 1990, um incêndio danificou ainda mais as já precárias condições locais. Depois disso, em 2011, houve uma obra de restauração da fachada e de um dos oratórios, cujo projeto previa inicialmente a transformação do beco em um boulevard, com bancos e vasos de plantas, mas que não chegou a ser realizado, apesar da abertura do processo de seu tombamento como Patrimônio Histórico da Cidade de São Paulo.

No entanto para os devotos, ao que tudo indica, nada disso tem importância. O local continua sendo visitado por aqueles que creem no poder de Chaguinhas interceder, junto a Deus, em favor dos que a ele recorrem. O registro de fotografias atesta a materialização da fé, expressão de gratidão e devotamento através de ex-votos, as placas votivas, além de fitas, velas e flores, exemplos concretos de uma devoção santoral, cujo entorno permite o entendimento desta e de outras manifestações populares de religiosidade, por diferentes segmentos da sociedade, assim como os avanços e recuos da Igreja Católica em relação a esta temática.

De forma generalizada, as expressões de religiosidade, assim como outros aspectos da vida social, fazem parte do sistema de vida de um grupo que, no campo religioso, envolve além da crença, um conjunto de práticas comportamentais. Nesse sentido, esta análise se apropria da afirmativa de Michel de Certeau que defende que "não se trata de elaborar um modelo para derramar neste molde o conjunto de práticas, mas, ao contrário, de especificar esquemas operacionais e verificar se existem entre eles, categorias comuns, e se em tais categorias, é possível explicar o conjunto de práticas” (1994, p. 20-21).

Assim, seguindo por essa trilha, de nosso estudo a um objeto concreto, a santificação popular de Chaguinha, o "santinho da Liberdade", transita do teórico para o concreto, do particular e do circunstancial ao geral, uma vez que as santidades populares apresentam elementos comuns, 


\section{Religiosidade popular na Capela dos Aflitos}

sobretudo o fato de prescindirem do aval institucional para se desenvolverem, mas cada qual guarda especificidades na sua construção e sua propagação. Enquanto alguns santos populares revelam a tragicidade de sua morte, outras expressam a resignação de longos períodos de enfermidade ou a precariedade da existência humana que só poderia ser explicada pela condição de excepcionalidade daquele que a suportou. De qualquer forma, o que vale é o sentimento de crença e fé no poder de alguns mortos para a resolução dos mais variados problemas da vida cotidiana, graças alcançadas, empregos, relacionamentos familiares, e sobretudo questões de saúde.

Em geral, no caso de Chaguinhas, como de tantos outros santos populares, as placas votivas, não identificam diretamente os devotos, nem explicitam o que foi alcançado, apenas agradecem. Bastante comum é a referência carinhosa ao santo nos ex-votos, como por exemplo "santinho" ou "meu santinho". E não raro identificamos mais de um reconhecimento do poder do santo, quando o devoto agradece "por mais uma graça alcançada".

Para além da crença em sua capacidade de interceder por seus devotos, há ainda a lenda de que o lugar seja assombrado e que à noite se pode ouvir gemidos e ver vultos com pescoços quebrados, em contínuo lamento ${ }^{12}$. Mas, apesar disso, pelo menos durante o dia, são deixados bilhetes com pedidos de graças, na porta do cômodo em que Chaguinhas teria passado suas últimas horas, ao sair da capela em direção à morte.

Essa devoção santoral, como outras tantas, é a expressão de um ritual que se verifica, de forma recorrente, em muitas capelas e igrejas e, em todos os cemitérios, grandes e pequenos, das grandes cidades e de pequenos vilarejos, em mausoléus ou em túmulos marcados pela simplicidade. São pessoas aflitas em busca de alento e de esperança, junto aos santos oficiais ou os oficiosos, quase sempre popularizados pelo seu sofrimento por ocasião de sua morte.

12 Vale questionar, no entanto, quem comprova tais fatos, caso contrário, relatos dessa ordem são remetidos somente ao imaginário popular, rico em casos e causos. 


\section{Religiosidade popular na Capela dos Aflitos}

\section{Referências}

AMARAL, E. Rótulas e Mantilhas. São Paulo: Civilização Brasileira, 1932. In: www.novomilenio. inf.br/santos/ho354a2.htm. Acesso em 11.dezembro.2017.

CAMARGO, L. S. de. Sepultamento na cidade de São Paulo: 1800-1858. https://tede2.pucsp.br/ hamd1e/hand1e/13014. Acesso em 10.dezembro.2017.

CASSIA, T. Movimento negro de base religiosa: a Irmandade do Rosário dos Pretos. Cadernos CRH, Salvador, 2001, n.34, p.165-179.

CERTEAU, M. A Invenção do Cotidiano: as artes de fazer. Petrópolis: Vozes, 1994.

ELIADE, M. Tratado de História das Religiões. São Paulo, Martins Fontes, 2010.

MOURA, P. C. São Paulo de Outrora: evocações da Metrópole. São Paulo: Itatiaia, 1980.

PONTES, J. A. V. São Paulo de Piratininga: de pouso à metrópole. São Paulo: Terceiro Milênio, 2003.

SAKURAI, C. Romanceiro da Imigração Japonesa. São Paulo: Ed. Sumaré/FAPESP, 1993.

www.arquisp.org.br/regiaose/paroquia/mosteiros-igrejas-historicas-oratorio-da-regiao-se/igrejanossa-senhora-dos-aflitos. Acesso 20.12.2017.

VAUCHEZ, A. Santidade. Enciclopédia Einaudi. Lisboa: Imprensa Nacional/Casa da Moeda, 1987, v.12, 287-300.

VOVELLE, M. Ideologias e Mentalidades. São Paulo: Brasiliense, 1987.

WOODWARD, K. L. A Fábrica de Santos. São Paulo: Siciliano, 1992.

Submetido em 05 de janeiro de 2021

Aceito em 20 de março de 2021

Publicado em 8 de julho de 2021 